\title{
BGS - EDUCATION THROUGH OPEN DOORS AND OPENGEOSCIENCE
}

All British Geological Survey authors: John Stevenson, Paul Denton and Kirstin Lemon (GSNI).

\section{ABSTRACT:}

The British Geological Survey (BGS) has supported geoscience education since it opened the Museum of Economic Geology in 1841. However, we have taken some large leaps since the wooden display cabinets of yesteryear and now the public can browse a geological map of the whole of the UK on their mobile phones, fly over or under the landscape using GeoVisionary or view and print our fossil collections in 3D. In 2010 the BGS opened its doors to its vast collections of data through Open Geoscience, which has stimulated opportunities to educate the public through a variety of online maps and free data. We also host events such as open days, 'rock detective' type clubs and attend science fairs to demonstrate our latest research or simply to educate and inspire the next generation of scientists. But nothing engages children's imagination like the destructive power of an earthquake. The BGS-led School Seismology project offers in-depth learning about the structure of the Earth through a set of simple classroom experiments and the opportunity to work with live data from real earthquakes. School seismology has become popular with teachers around the world and will shortly venture into space to explore the seismology of Mars. 


\section{BGS - EDUCATION THROUGH OPEN DOORS AND OPENGEOSCIENCE}

The British Geological Survey (BGS) has supported geoscience education since the Museum of Economic Geology opened in Whitehall, London, in 1841. Throughout its long history the Survey has been closely associated with museums by carrying on the Victorian tradition of public education via the display of rocks, fossils and minerals. However, we have taken some large leaps since the wooden display cabinets of yesteryear and now the public can browse a geological map of the whole of the UK on their mobile phones, fly over or under the landscape using GeoVisionary or view and print our fossil collections in 3D.

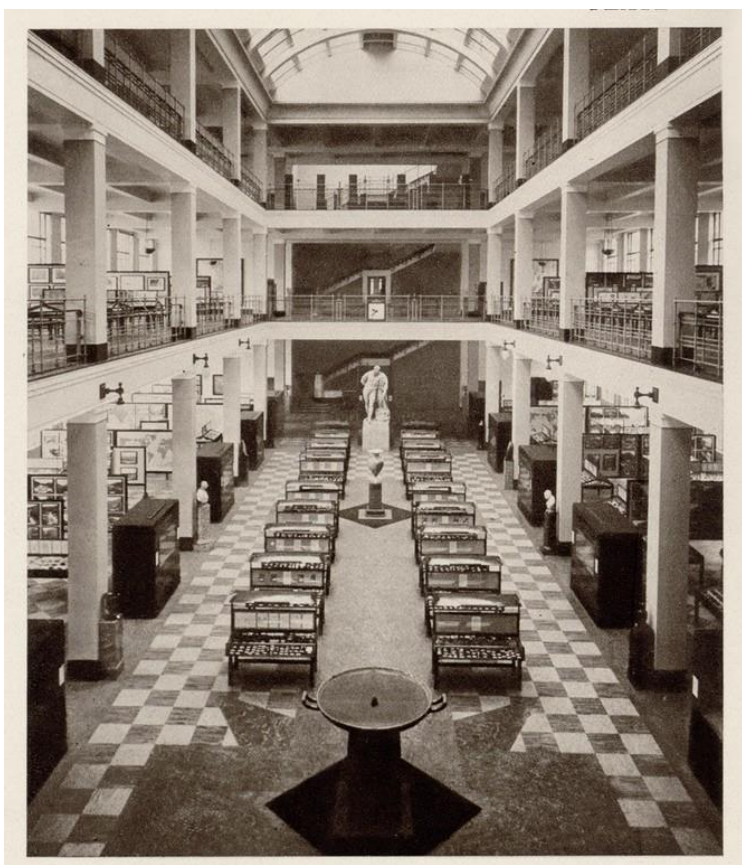

NEW MUSEUM, SOUTH KENSINGTON : Interior View

Figure1. The BGS 'geological museum' at its third home in South Kensington c.1930, now part of the Natural History Museum.

\section{SUMMER OF SCIENCE}

Since 1965, the BGS has been part of the Natural Environment Research council (NERC), which is the leading funder of independent research, training and innovation in environmental science in the UK. The NERC encourages its research centres to Pre-publication version 7 July 2015 
communicate its research work as widely as possible, to inform and enthuse non-scientific audiences about environmental science and to demonstrate the economic and societal benefits that science brings.

It's a fortunate coincidence that the Education in the geosciences edition of TLE coincides with the NERC's $50^{\text {th }}$ anniversary, celebrated as the Summer of Science. NERC researchers will be taking their work and enthusiasm out to the public, branching out from the usual science festival venues into shopping centres, music festivals, pubs and even beaches! We launched our new Climate Through Time floor map on the pebbled beach at the Lyme

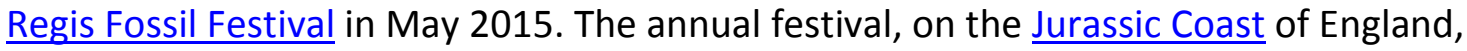
attracts about 10000 visitors. The theme of the festival was 'Mapping the Earth', to celebrate the 200th anniversary of William Smith's geological map. In keeping with the theme, the BGS stand was based around an 'immersive' $4 \mathrm{~m} \times 5 \mathrm{~m}$ Climate Through Time (BGS, 2008) map. The map literally allows people to walk around the British Isles and explore the links between our planet's changing climate and the rock-forming environments that have varied through geological time; supported by some giant Lego and some handy rock sets. 


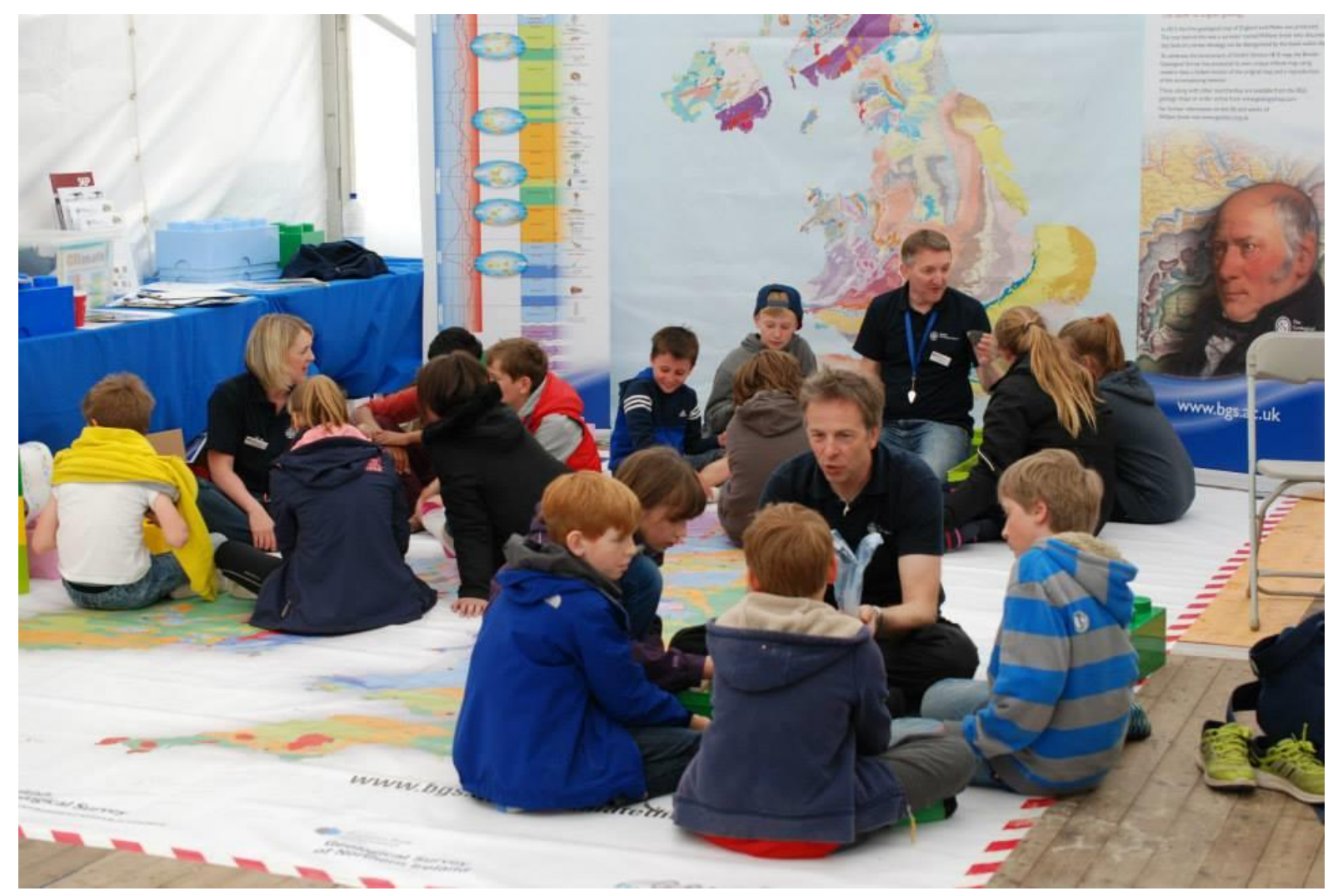

Figure 2. The BGS Climate Through Time giant floor map on the 'schools day' at the Lyme Regis Fossil Festival, May 2015.

\section{WHAT ISN'T EDUCATIONAL MATERIAL?}

Geoscience education reaches into so many parts of the BGS it is difficult to know where to start and what qualifies as 'pure' education. The focus of this article will be on education for the public and exclude peer-reviewed research papers, geological maps, 'memoirs' and licensed data that are primarily intended for the professional user; although we know that university students use BGS maps when they go into the field to practise survey techniques as well as our regional guides. 


\section{OPENGEOSCIENCE}

Many of the BGS's educational activities mentioned below are part of the Open Geoscience initiative. Launched in 2010, Open Geoscience is a free service that lets you view maps, scans photos and download data.

- online data and free data downloads

- $\quad$ publications - free downloads, printed maps and guides

- materials collections online as scans

○ photographs

- software

- websites and web services

○ apps

$\circ$ discovering Geology website

- map downloads and web services - national scale geology maps and cross sections

○ map viewers

We encourage users to mash-up OpenGeoscience material with their own data in new and innovative ways by adding new functionality or interfaces. The BGS website shows lots of examples of data mash-ups from geological trails to teaching resources from Earth Learning Idea.

$$
\text { VIDEO, BLOGS AND SOCIAL MEDIA }
$$

The BGS has been Tweeting and Facebooking since 2008 and has acquired over 36000 followers on our 'main' pages. It has have always valued social media as a public 
engagement tool and are never surprised when new followers remark, 'haven't there been a lot of earthquakes recently'? Comments like these make us appreciate that we are reaching new and previously 'hard-to-reach' audiences.

$\underline{\text { Video }}$ and $\underline{\text { blogs }}$ also provide an informal publishing route to educate new audiences. Recently we have produced a number of Geology Shorts; YouTube videos where our scientists explain their work using no jargon and no PowerPoint slides. Many of our videos, and other website resources, are recommended as a teaching resources on the TES website.

\section{CAN YOU TAKE A TABLET TO IMPROVE YOUR GEOLOGICAL KNOWLEDGE?}

Over 60 per cent of the UK population own a smartphone; ownership is about 90 per cent of 16 to 24 year-olds (Ofcom, 2014). Trends show that people spend significantly more time on their mobile devices when compared to their PCs. The BGS has several free apps to meet this demand, but our iGeology app leads the way in reaching users that may never have considered buying a geological map but want to learn more about the ground beneath their feet. iGeology consistently receives good feedback, but we are listening to our users by developing offline resources so users don't get frustrated when they can't get a good mobile signal out in the field. Downloads of iGeology have exceeded 250000 since its launch in 2010. 


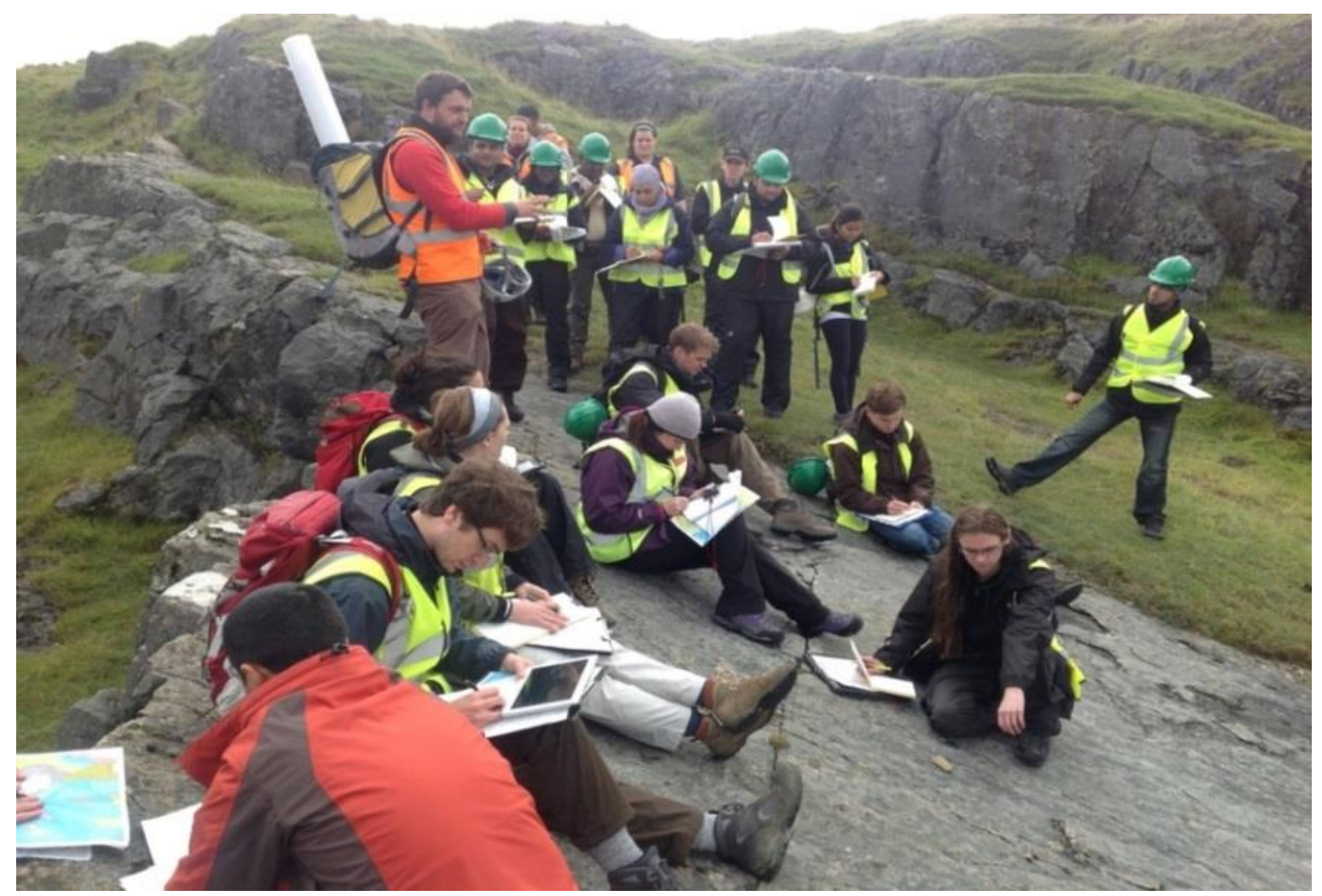

Figure 3. Leeds University geology students evaluating BGS mobile and tablets apps at Ingleton, North Yorkshire.

\section{EVENTS AND OPEN DAYS}

The BGS has a long history of working with the British Science Association to put on educational events for schoolchildren and the public, such as British Science Week (BSW). We also encourage our staff to become STEM Ambassadors so that they can inspire and enthuse the next generation of scientists, either in schools or at public events. The BGS has participated in BSW, or National Science and Engineering Week as it was previously known, since it began in 1994. Our goal is encapsulated in the parent feedback from the 2015 BSW event.

'Absolutely brilliant. Loads of interactive activities that kept us interested all day. 
Please convey our thanks to all those who kindly gave up their Saturdays to share their knowledge and enthusiasm for geology with so many people. The place was buzzing and we went away feeling very inspired by all we had seen.'

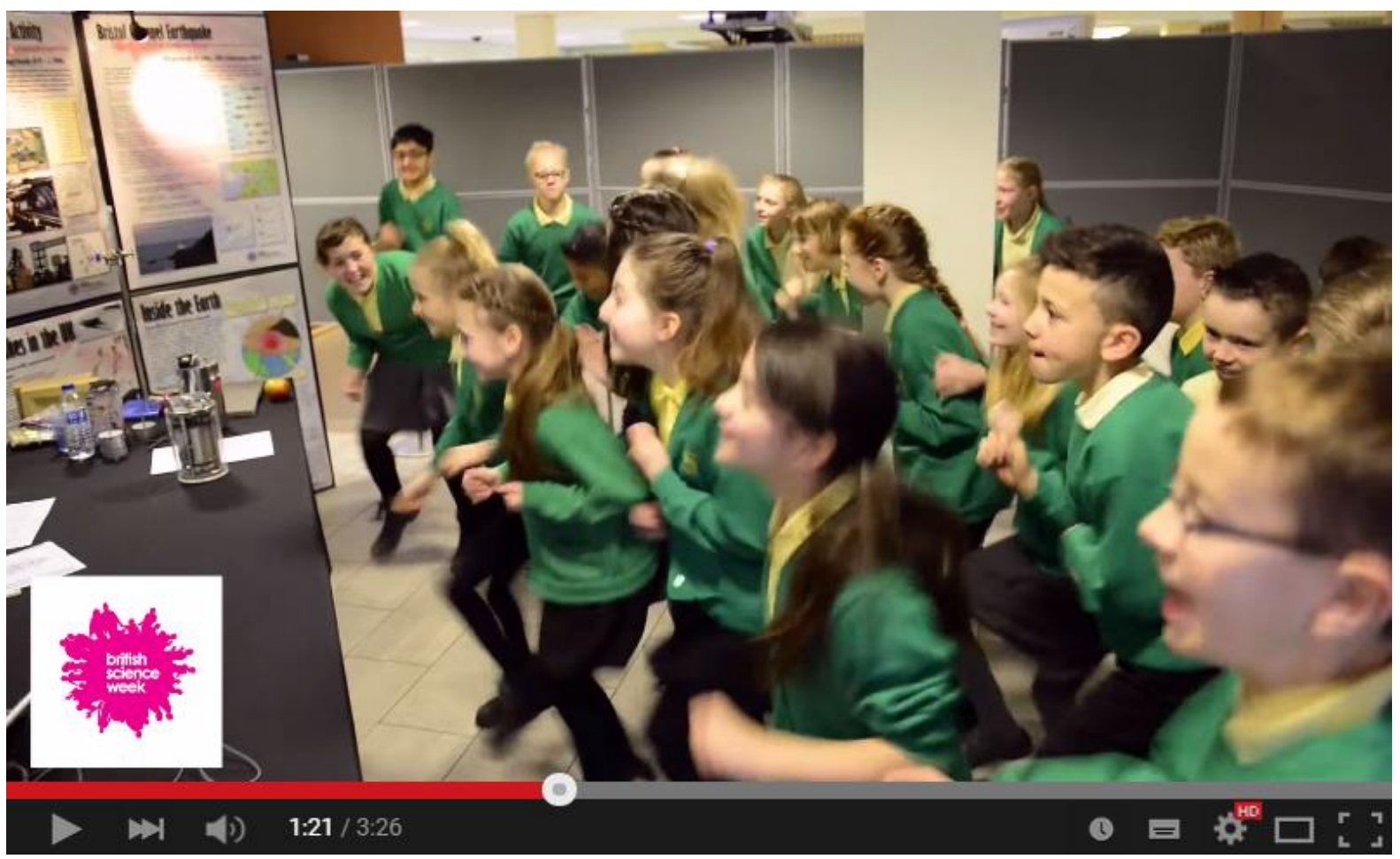

Figure 4. Schoolchildren have been making their own earthqakes at the BGS British Science Week events since 1994.

Our office in Edinburgh has opened its doors to the public for an annual event since the early 1980s. The BGS in Edinburgh has long recognised the value of presenting its work and activities to the general public in a more relaxed and informal way, so the Open Day is seen as vitally important in bringing people, especially schoolchildren into contact with the work of the Survey and in explaining its relevance in a rapidly changing world.

The BGS at Nottingham went 'big' for its recent 2015 Open Day, in celebration of the NERC Summer of Science, and brought together an event to include six NERC institutes, several universities and the London Volcano. This event also included our popular Geological Walk 
and GeoVisonary '3D cinema'. We also roll out these demonstrations for the monthly site tours of our Nottingham office.

\section{THE GEOPARK EFFECT}

The Geological Survey of Northern Ireland (GSNI), which is part of the BGS, has played a pivotal role in developing geoscience education in Northern Ireland in recent years. A large part of this has been due to the close working relationship that the GSNI has with the Marble Arch Caves Global Geopark. One of the Geopark's primary functions is to develop and deliver educational resources that encompass the whole spectrum of the education sector. Many of these have been developed by the GSNI and include:

- Rock Detectives Clubs: A series of interactive workshops was developed based on the geology of the local area and delivered as part of Heritage Week. There were two levels of workshop aimed at 4 to 8 year olds and 8 to 12 year olds and included activities such as making your own planet Earth, digging in glacial sand, fossil hunting and making your own toothpaste. This series of workshops was awarded Best Children's Event by the Heritage Council out of over 700 events that took place throughout the island of Ireland during Heritage Week.

- Rock Detectives Workbooks (Lemon, 2015): To complement the Rock Detectives Clubs, a more formal workbook was developed to meet the requirements of the World Around Us element of the Northern Ireland primary curriculum, and the Social, Environmental and Science Education of the Republic Ireland primary curriculum. These have been accompanied by a number of familiarisation visits for primary school teachers in the local area. 
- Our Outdoor Classroom: Designed to be used to self-guide geography and geology teachers to numerous sites within the Geopark, this book provides information on the geology and geomorphology at each site, practical information, activities that could be carried out, and the relevance to the specification.

- Science Week Workshops: This series of eight workshops was designed to focus on elements of the local geology and were run simultaneously for large groups of schoolchildren. The workshops were delivered by Geopark staff and a resource pack was prepared for teachers so that they could replicate the workshops at school as well as providing suggestions for follow-up activities.

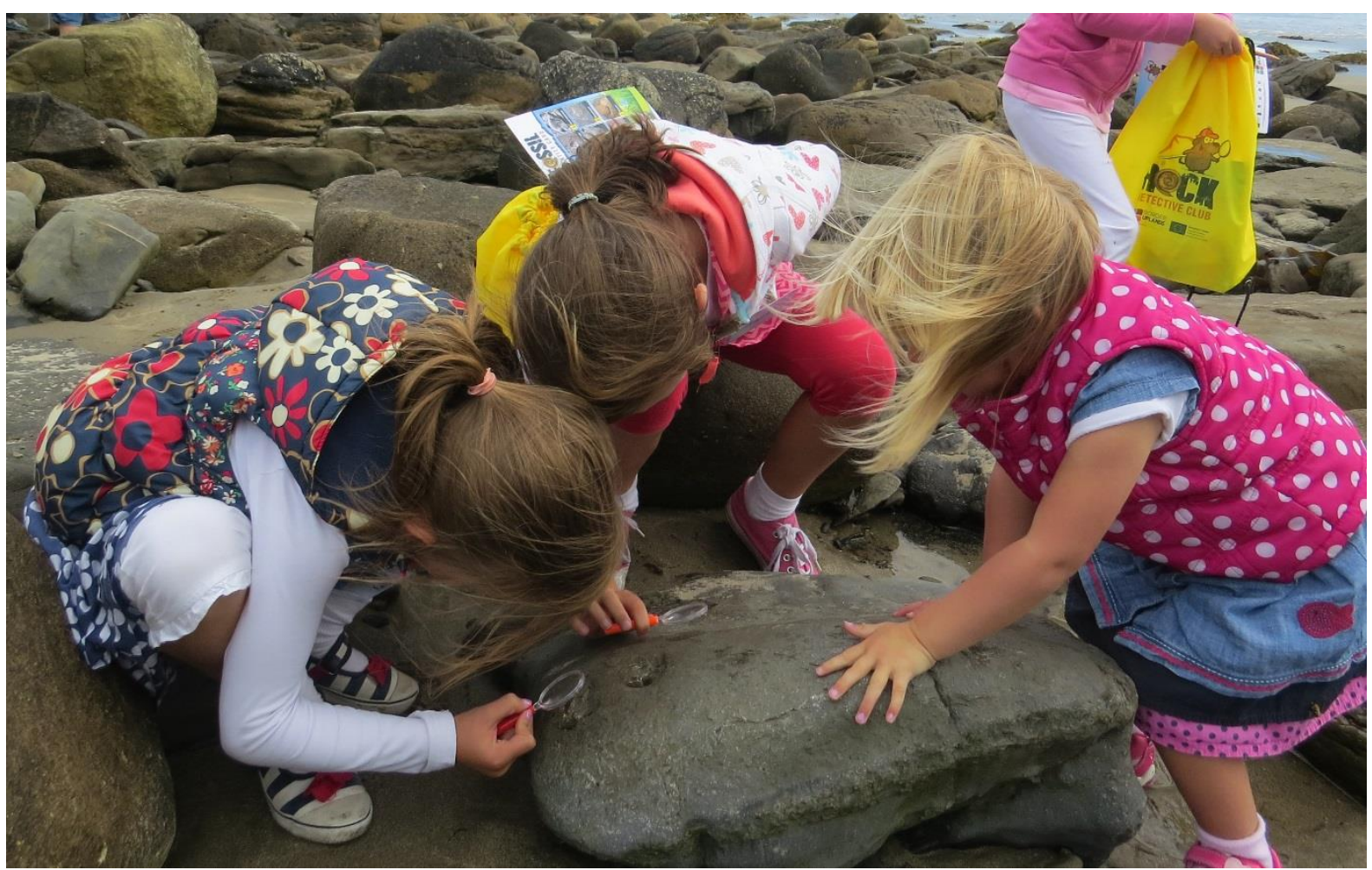

Figure 5. Young Rock Detectives get out their hand lenses to inspect the beach boulders at Sligo, Ireland. 
In addition to the work carried out in association with the Marble Arch Caves Global Geopark, the GSNI has produced a number of resources designed to address the fundamental lack of geoscience education in Northern Ireland as a whole.

Together with Earth Science Ireland, the GSNI has developed a suite of lesson plans and associated resources designed to provide teachers with the tools to teach elements of geosciences as part of the World Around Us (Key Stage 2) element of the Northern Ireland Primary Curriculum. This project was completed together with a number of local primary school teachers, and has been circulated to all 832 primary schools across Northern Ireland.

The GSNI also produced a publication together with NI4Kids, a magazine aimed the parents of primary schoolchildren, to try and enthuse and educate children aged between 4 and 10 about geoscience. The publication entitled, geology4fun: Discovering Northern Ireland's rocks and landscapes (GSNI, 2014) identifies 12 sites across Northern Ireland for parents to visit with their children and gives them a basic interpretation as well as practical information including how to get there. Each site has a supporting activity that could be carried out at home that aims at demonstrating key geological principles in an interactive and easy-to-understand manner.

\section{EMBEDDING EDUCATION IN SCHOOLS PROGRAMMES}

The BGS is probably not unusual in having a small public engagement/outreach team and a correspondingly small budget. How do you reach out to schools with a few staff and limited resources? The simple answer may be to provide excellent web resources and to embed science education projects within schools on a national scale.

The BGS Discovering Geology website attracts about 4000 visitors a day, which seems an effective way to deliver geoscience education. Resources like the BGS Make-a-map and Pre-publication version 7 July 2015 
Timechart have always been popular, but they don't really lend themselves to extended learning or scientific experiments like the well-established School Seismology project and the fledgling MarsQuake project; the geophysicists lead the way!

\section{SCHOOL SEISMOLOGY}

The BGS leads the UK School Seismology project; an educational seismology project aimed at inspiring and enthusing school students in their studies of science and geoscience in particular. The project was launched in 2006 and has seen over 500 schools across the UK install simple observational seismometer systems capable of detecting signals from large earthquakes anywhere in the world.

The UK project arose out of a need to improve participation rates in school sciences, especially physics. In the 1990s, the number of students studying physics had dropped by 50 per cent. Universities running geosciences degree courses at undergraduate or postgraduate levels were struggling to recruit good students to their courses and the major employers of geosciences graduates in the UK were suffering recruitment problems as a consequence.

Initial discussions with a small focus group of secondary school science teachers led to a number of conclusions:

1) The use of practical observational seismology in a UK school environment was thought to be an excellent context for teaching a wide range of basic science topics.

2) Given the choice between a research-quality seismometer in a 'black box' enclosure and a simple mechanical sensor with a visually open design, the teachers all preferred the simple mechanical design. 
Each year in the UK, a seismometer station located in an urban environment is likely to detect, above background noise, less than ten local earthquake signals (from UK or Europe) but over 50 teleseismic earthquakes, mostly from the Pacific Rim. In order to be able to detect the large amplitude surface waves with peak frequencies around $0.05 \mathrm{~Hz}$ from these teleseismic events, a simple mechanical seismometer needs to have a natural period of 20 seconds or longer. The UK school seismology instrument was chosen as a version of the garden-gate, suspension-horizontal-pendulum system, designed and manufactured by engineers from Mindsets, a long-established school science equipment provider.

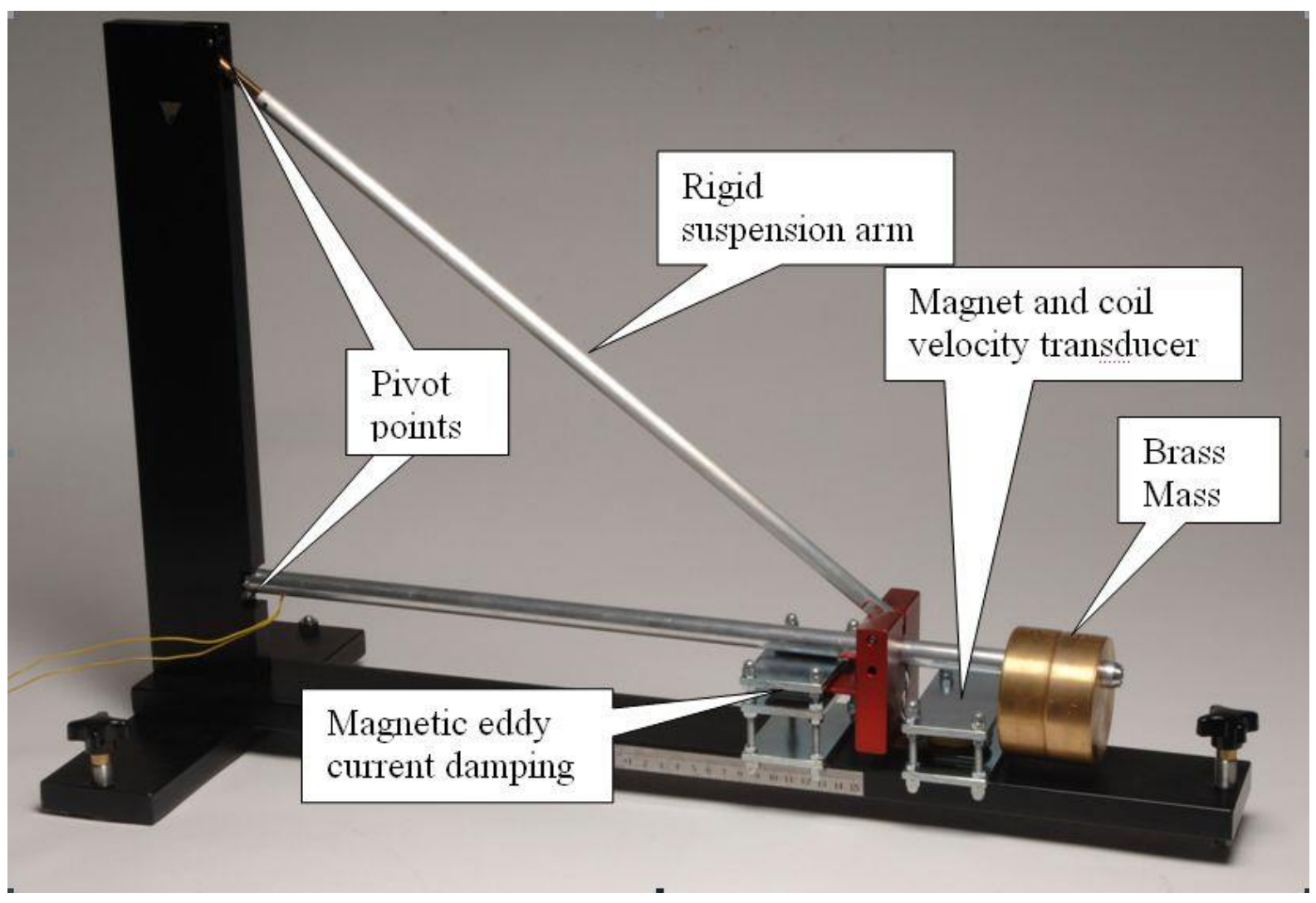

Figure 6. The Mindsets UK SEP seismometer; a horizontal seismometer that uses electromagnetic induction to detect ground motion (velocity) with eddy current damping. The school seismometer system, complete with amplifier/digitiser electronics package, was designed to be compatible with the existing AmaSeis seismic data logging and analysis 
software, which had been written specifically for school use in the USA, and was launched in 2007 together with a tried and tested set of classroom science activities that all had seismology and earthquakes as a linking theme (Denton, 2008). During the first two years of the project, over 200 instruments were donated to schools through generous funding by the Petroleum Exploration Society of Great Britain and the Scottish Oil Club. The BGS manages the UK School Seismology project by promoting the project to teachers and running training workshops in how to use the resources in partnership with university earth science departments around the UK.

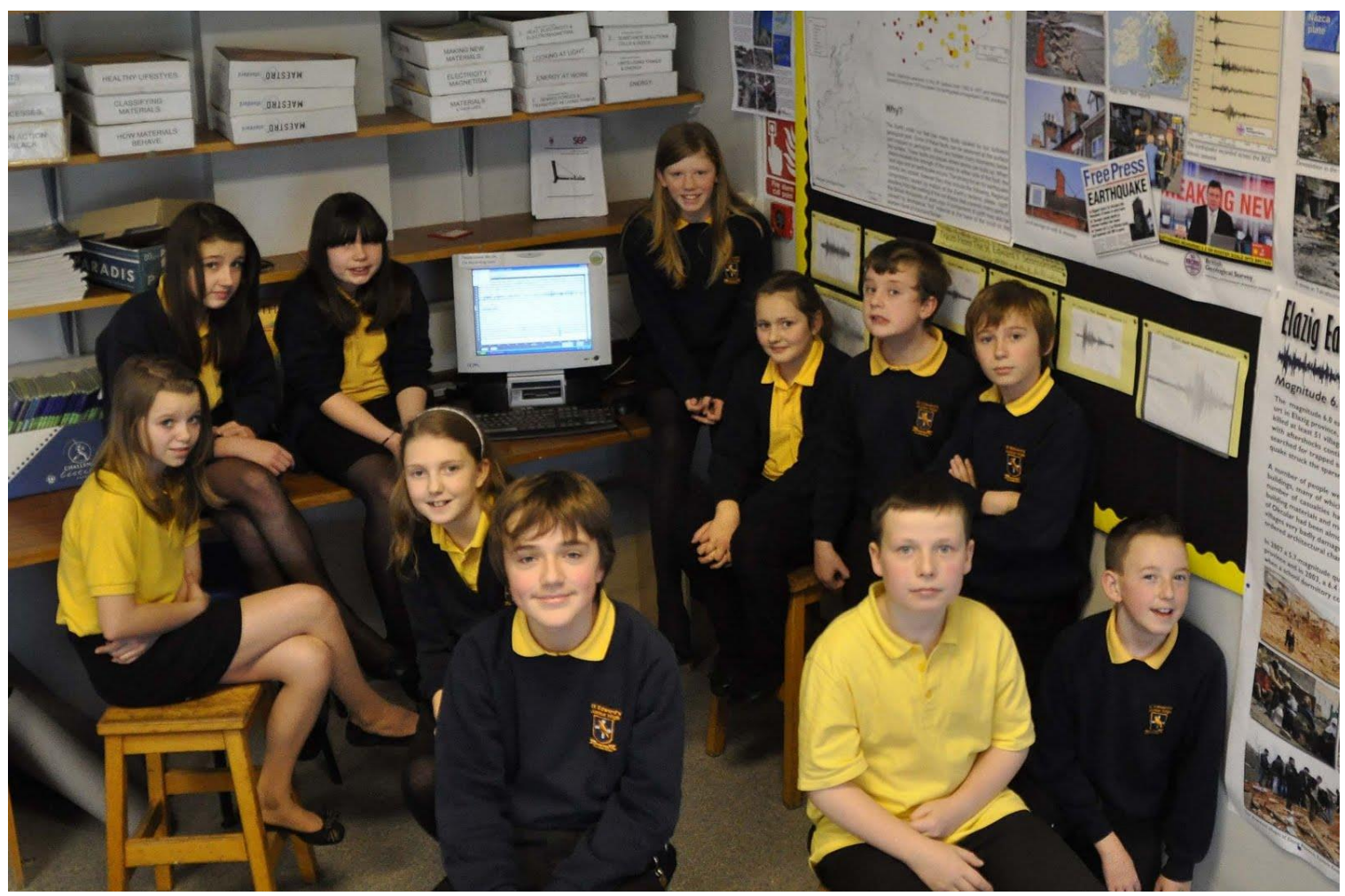

Figure 7. The UK School Seismology project continues to support schools wishing to engage in observational classroom seismology and now has strong links with similar programs in Australia, France, Ireland, Italy, Portugal, Romania, Switzerland, New Zealand and the USA. 


\section{MARSQUAKES}

The need to inspire the next generation of geoscientists is as pressing now as it has ever been. Space has always been an inspirational context for science education and in 2016 BGS will be launching a new educational initiative in collaboration with the National Space Academy in Leicester to look at MarsQuakes.

In 2016 NASA will send the INSIGHT mission to Mars, as part of its scientific payload this lander will carry a sensitive seismometer built at Imperial College in London. Data from this mission will be beamed back to earth and distributed to interested users. It offers our first chance to look at extra-terrestrial quake data since the Apollo moon missions.

The MarsQuakes education programme will look at how scientists expect to understand and analyse the seismic data returned from Mars and will include

- high-resolution imagery activities for identifying new meteorite impact sites on Mars using HiRise orbiter data

- classroom-impact investigations using sandboxes and marbles

- $\quad$ seismic-wave investigations using slinkies and people-particles

- $\quad$ single-station event location using P-S travel times and $X / Y$ particle motion plots

- event location studies using data from classroom experiments, Earth, Moon and Mars

- $\quad$ seismic-sensor studies using MEMS accelerometers and homemade geophones

Educational programmes will be co-ordinated with partners in the USA, France, Germany and Switzerland, who are also involved in the INSIGHT mission. We expect to start training teachers in April 2016 so that they are ready to start looking at data from Mars as soon as it is available, which should be around December 2016. 


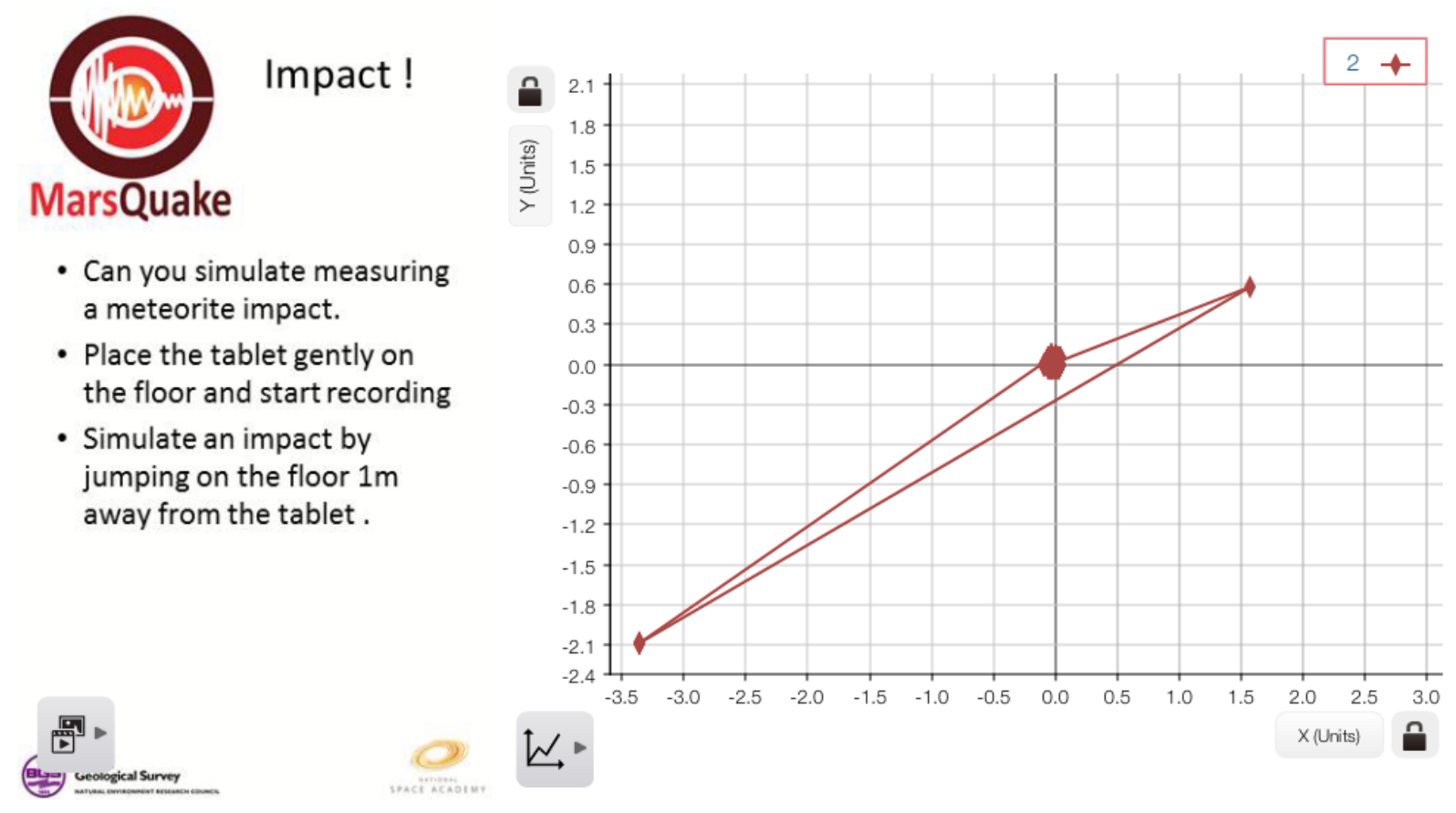

Figure 8. Working with partners, we are developing classroom resources that use the builtin accelerometer of Android or Apple tablets, running free software, to produce a set of simple experiments on P-S waves and locating earthquakes from a single sensor.

\section{DOESN'T THE BGS DO OTHER SCIENCE?}

There are lots of pockets of other great educational geoscience activity underway at the BGS that include:

- Carbon capture and storage

- $\quad$ Raspberry Pi Magnetometer

- GeoVisionary as an education tool; including virtual field trips

- Groundhog - Virtual borehole and action viewer; including 3D models

- Seconds from catastrophe - Living with an active volcano 


\section{WHAT'S NEXT?}

The longevity of the UK School Seismology project demonstrates that embedding simple science activities into schools programmes is successful. We have also started to work with schools and educators to develop the use of Minecraft as a learning tool to investigate the subsurface. In 2014, we launched a Minecraft geology map of the UK. Our next step is to work with partners to develop a resource that can be used within the classroom to teach geography and geology through playing in a familiar and easy-to-use 3D GIS environment; familiar to kids that is! 


\section{REFERENCES}

BGS, 2008, Climate Through Time - Our rocks reveal the story of change: (Keyworth, Nottingham: British Geological Survey.)

Denton, P., 2008, Seismology in Schools: 10 years on: Astronomy and Geophysics, 49, No. $6,6.13-6.14$

GSNI, 2014, Geology4fun: Discovering Northern Ireland's Rocks and Landscapes;

Geological Survey of Northern Ireland.

Lemon, K., 2010, Our Outdoor Classroom: A teaching resource guide to the Marble Arch Caves Global Geopark: Cavan County Council.

Lemon, K., 2015, Rock Detectives Workbook: Discovering the Geology of Cavan, Fermanagh, Leitrim and Sligo: Border Uplands Project \& Geological Survey of Northern Ireland.

Ofcom, 2014, Adults' Media Use and Attitudes Report. 